\title{
DEVELOPMENT OF A METHOD FOR IDENTIFYING THE STATE OF HEALTH IN AUTOMOTIVE BATTERIES OF THE LEAD-ACID TYPE
}

\author{
Iolanda Chamusca ${ }^{a}$, Brenda Moret ${ }^{a}$, Giovanni Malisano ${ }^{b}$, Marco Marcassa $^{b}$, Nelson \\ Timbó $^{b}$, Roberto Costa ${ }^{c}$, Rodolfo Exler ${ }^{d}$ \\ a Production Engineering, Centro Universitário SENAI CIMATEC, Brazil \\ ${ }^{b}$ Electrical Engineering, Centro Universitário SENAI CIMATEC, Brazil \\ c Product Development, Ford Motor Company, Brazil \\ ${ }^{a}$ Associate Professor, Centro Universitário SENAI CIMATEC, Brazil
}

\begin{abstract}
The automotive industry has been looking for innovative low-cost solutions that attract attention of the final consumer, influencing their purchase decision. In the context of Rota 2030 Program, a Brazilian government strategy, this study pursued a solution that warns the imminent failure of lead-acid batteries used in combustion vehicles. Thereunto, a method for calculating the State of Health $(\mathrm{SOH})$ of lead-acid batteries was proposed, with the potential to solve the problem of pre-failure warning, without adding hardware to the vehicle, ensuring a low-cost solution. As it is implementable, this method was developed in a personalized way and indicated as a solution for the partner automaker, which provided the vehicles for the necessary data collections.
\end{abstract}

Keywords: Lead-Acid-Battery; $\mathrm{SOH}$; Combustion vehicle; Internal resistance; Automotive industry.

\section{DESENVOLVIMENTO DE MÉTODO PARA IDENTIFICAÇÃO DO ESTADO DE SAÚDE DE BATERIAS AUTOMOTIVAS DO TIPO CHUMBO ÁCIDO}

Resumo: A indústria automotiva vêm buscando soluções inovadoras de baixo custo que atraiam a atenção do consumidor final, influenciando na sua decisão de compra. Visando o Programa Rota 2030, estratégia do governo brasileiro, o presente estudo buscou uma solução que sinalize a eminente falha das baterias utilizadas nos veículos à combustão. Para isso, foi proposto um método de cálculo do nível de saúde (SOH) das baterias de chumbo-ácido, com o potencial de sanar o problema de sinalização de falha, sem adição de hardware ao veículo, garantindo baixo custo para a solução. Por ser implementável, esse método foi desenvolvido de forma personalizada e indicado como solução para a montadora parceira, que cedeu os veículos para as coletas de dados necessárias.

Palavras-chave: Bateria-de-chumbo-ácido; SOH; Veículo à combustão; Resistência Interna; Indústria Automotiva. 


\section{INTRODUCTION}

The automobile industry has revolutionized transportation, giving a new meaning to the possibilities of mobility. In Brazil, this branch of industry has been guided by the Rota 2030 Program - Mobility and Logistics, a Federal Government strategy for the development of the automotive sector in the country. This fifteen-year plan has some policies to encourage research and development (R\&D), aiming to provide companies with instruments so they can reach the established goals [1].

One of the challenges faced by the national automotive industry to be solved by Rota 2030 is the technological gap, especially in energy efficiency, structural performance and drive assistance technologies. Part of this problem can be associated with some conditions of lead-acid batteries, presented in most vehicles in the Brazilian market. The large application of this battery is motivated by its reliability, safety and low cost, highlighting the continuous economic and technological importance of studies, improvements and advances in the area [1] [2].

Since the lead-acid battery is the key component to crank a combustion vehicle, its premature failure, or exhaustion, before the predicted period, can cause losses to the user experience. From a business perspective, it's important to avoid such inconveniences, becoming essential to obtain accurate and reliable parameters for the battery State of Health $(\mathrm{SOH})$ measure. These parameters enable studies on the current condition of lead-acid batteries, avoiding cars sales with compromised battery and perform predictive maintenance with greater precision in the diagnosis process [3].

Therefore, the following study was proposed in 4 sections, aiming to present a method to estimate the lead-acid batteries State of Health (SOH). The first section introduces preliminary information and background studies available in the academy; the second section details the methodology used to collect data and estimate $\mathrm{SOH}$ in a practical application; the third section discusses the results of generated graphs and images. The last phase concludes this workstream with a software solution proposal, without adding components, modules or hardware, in addition to those already present in the electrical system of the evaluated cars.

\subsection{Basic SOH estimation method}

The state of health $(\mathrm{SOH})$ quantifies battery degradation. Thus, a brand-new battery, without fabrication flaws, has a $100 \% \mathrm{SOH}$ and an end-of-life battery has $0 \%$ $\mathrm{SOH}$, achieving the minimum operational performance [4]. The proposed studies for the battery capacity loss quantification models have their applications bounded by availability of data that characterize the battery and the possibility of obtaining it in different circumstances of vehicle use.

With these considerations, the model proposed by I-Kun et al. [5] stands out, in which the $\mathrm{SOH}$ calculation can be performed based on the lead-acid battery internal resistance values, obtained from current and voltage reading during vehicle's engine cranking periods. Thevenin's electrical circuit is used during charge and discharge cycles to analyze which characteristic best indicates battery degradation. The instantaneous voltage profile is considered immediately after charging, ruled by the internal resistance $\mathrm{R} 1$, and a transient period in the overvoltage resistance $\mathrm{R} 2$ and capacitor $\mathrm{C}$, checking which parameter better represents $\mathrm{SOH}$ decay as represented in Figure 1 [5] [6]. 
Figure 1. Thevenin circuit for charge and discharge. (Based on I-Kun et al. [5])

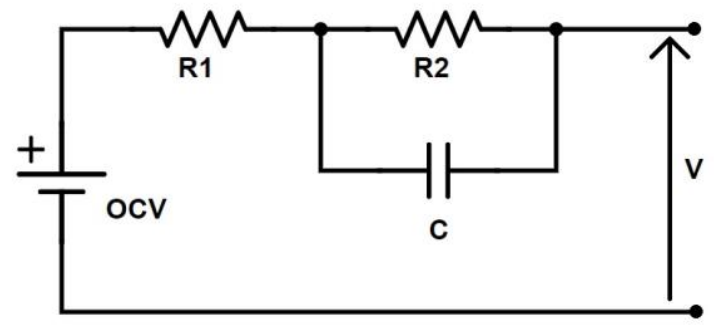

To test a battery with decayed $\mathrm{SOH}$, an artificial deterioration process is used, which consists in charging a new battery completely and discharging it completely. After repeated degradation, it becomes clear that the battery internal resistance value is inversely proportional of $\mathrm{SOH}$, for periods of charging and discharging. If the electrolytic module provides enough energy for the application, more degradation cycles are performed until the battery is no longer able to maintain the vehicle's electromechanical systems properly functional, indicating SOH deterioration.

For $100 \%$ SOH determination, it's necessary to fully charge a brand-new, never used before battery and measure its voltage and current when the vehicle starts. With these values, internal resistance is determined from Ohm's law, which can be used as a parameter for good health. A $100 \%$ SOH battery has low resistance values, while a $0 \% \mathrm{SOH}$ is usually found in batteries with high resistance values, which is relative to the battery model. For practical implementation, the SOH calculation model is strongly dependent on the vehicle's brand and electrical systems configurations.

\subsection{Vehicle internal network - CAN}

The Controlled Area Network (CAN) bus uses digital data transmission, enabling the creation of communication protocols provided with verification routines to guarantee the security and integrity of the transmitted message. As it follows the multimaster network standard, there is no hierarchy between modules on the CAN bus, allowing for direct interaction between modules and controllers, discarding the need for a central module to manage interactions [7].

The interactions between modules, associated with the creation of codes and addressing, conceived the Parameter Identification (PID). This format consists of defining a code (aka address) to reference a specific variable.

Understanding the principles of operation of a lead-acid battery and the prevalidated methods for its calculation of $\mathrm{SOH}$ level, it is possible to conclude which indicators, or PIDs, must be extracted from a vehicle to infer the SOH level. Therefore, considering the adoption of different PID codes by each vehicle manufacturer, the calculation of state of health (SOH), based on PID codes, must be obtained in a personalized way, adjusting each OEM PID strategy per vehicle line.

\section{METHODOLOGY}

\subsection{Data collection}

In order to identify the state of health of the battery, some PIDs, already implemented by the vehicle manufacturer, were selected to execute this study. The 
technical information about these PIDs were shared by the manufacturer through a partnership and confidentiality agreement, therefore only the data outcome results were included in this paper.

A smartphone application, developed by the automaker, was used to PID data extraction from each vehicle. The relevant PIDs to the battery behavior were chosen, however, considering the premises discussed in the previous sections, only 8 PIDs were considered to calculate the SOH level. They are as follows: Vehicle Identification Number, State of Charge, Vehicle Battery Voltage, Vehicle Battery Current, Crank Duration - Cold Start, Cranking Current during last engine start, Cranking Voltage during last engine start and Vehicle Battery - Time in Service.

The acquisitions were made in vehicles containing a BMS (Battery Monitor Sensor). This module is found on the battery negative pole and made it possible to measure the necessary parameters. The selected vehicles use batteries with a capacity of 60 Ah and CCA (Cold Cranking Amps) of 440A. The chosen vehicles were divided in subgroups as described below:

I. Newly assembled cars.

II. Vehicles between one and two years of usage, with an already used battery.

To collect vehicle data, in addition to the app, the OBDLink LX diagnostic device was used. The data was sent by the device to a smartphone via Bluetooth, and the communication was stored in a text file inside the smartphone after the acquisition process was completed. The information contained in this file was the raw communication happening in the CAN bus. Since the data traffic is recorded in the file as hexadecimal data, the data still had to go through a conditioning algorithm to be decodified.

An example of this translation sequence can be seen at Table 1. The PIDs used for this demonstration are the Vehicle Battery Voltage and Vehicle Battery Current. The values obtained in base 16 (hexadecimal) were converted to base 10 (decimal) according to their data identifier. Finally, corresponding formulas were applied to obtain the values in their respective units of measurement. The data in Table 1 didn't reflect the real translation due to confidential agreement with the automaker.

Table 1. PID conversion steps

\begin{tabular}{|l|c|c|c|}
\hline PID & HEX & BASE 10 & Converted \\
\hline Vehicle Battery Voltage & 6312 F7 84 & 132 & $13,4 \mathrm{~V}$ \\
\hline Vehicle Battery Current & 6312 B9 7D & 125 & $-15 \mathrm{~A}$ \\
\hline
\end{tabular}

With the translated data in hand, the study started to be focused on the method construction for the lead-acid batteries state of health $(\mathrm{SOH})$ calculation, based on a percentage scale. For this, I-Kun et al. [5] article was used as background study, that describes a method based on batteries internal resistance values as a parameter to measure the percentage level of $\mathrm{SOH}$.

\subsection{SOH estimation in practical application}

Scale definition was made using the lead-acid battery internal resistance as the main parameter, being a good or bad $\mathrm{SOH}$ indicator. This scale ranges from $0 \%$ to 
$100 \%$, inversely proportional to the internal resistance value. The equation 1 was obtained to quantify the battery's SOH percentage:

$$
S O H_{\%}=100-\frac{100 *\left(x-R_{i}\right)}{R_{r}-R_{i}}
$$

SOH's behavior was represented with internal resistance initial value close to zero, equivalent to $100 \% \mathrm{SOH}$ level. With the increase of internal resistance associated with battery decay, the $\mathrm{SOH}$ level approachs $0 \%$. Thus, the constant $\mathrm{Ri}$ represents the internal resistance of a brand-new battery, $\mathrm{Rr}$ represents a decayed battery in process of failure, and $x$, the measured battery.

Parameters measurements must be done continuously until a significant increase in internal resistance is detected, indicating a compromised $\mathrm{SOH}$. Analyzing the model proposed by I-Kun et al. [5] it was possible to link his studies with vehicle's communication, developing an algorithm able to calculate $\mathrm{SOH}$ percentages using information already available. This algorithm is valid for lead-acid batteries with high states of charge (SOC), since low SOC values may affect $\mathrm{SOH}$ estimation. Here, an alert should be generated to the user through an HMl (Human Machine Interface) platform on the vehicle, like the navigation screen used as central multimedia. Some concept images were created using Photoshop representing an HMl application, shown in next section.

\section{RESULTS AND DISCUSSION}

Through the measurements on newly assembled vehicles containing new batteries, the average internal resistance of $27,6 \mathrm{~m} \Omega$ was calculated, being defined as the representative of $\mathrm{SOH}$ in $100 \%$. The defined internal resistance value for $0 \%$ was $40 \mathrm{~m} \Omega$, based on the internal resistance values presented by I-Kun et al. [5], to represent resistance in batteries with low $\mathrm{SOH}$. The same concept was carried out to vehicles in use, the second data collection group, as seen in Table 2, where the $\mathrm{SOH}$ results were obtained. In this example, only cars with battery SOC above $80 \%$ had their SOH calculated, while cars with battery SOC below $80 \%$ show the message "SOC Low", not calculating the SOH:

Table 2. Application of method in vehicles

\begin{tabular}{|c|c|c|c|c|c|c|}
\hline Car & $\begin{array}{c}\text { State of } \\
\text { Charge } \\
(\%)\end{array}$ & $\begin{array}{c}\text { Time in } \\
\text { Service } \\
\text { (days) }\end{array}$ & $\begin{array}{c}\text { Cranking } \\
\text { Voltage } \\
\text { (V) }\end{array}$ & $\begin{array}{c}\text { Cranking } \\
\text { Current } \\
(\mathbf{A})\end{array}$ & $\begin{array}{c}\text { Internal } \\
\text { Resistance } \\
(\mathbf{m} \Omega)\end{array}$ & $\begin{array}{c}\text { \% State of } \\
\text { Health }\end{array}$ \\
\hline $\mathbf{6 6}$ & 80 & 461 & 9,621094 & 387,072 & 24,86 & Low SOC \\
\hline 67 & 94 & 517 & 9,480469 & 250,992 & 37,77 & 17,96 \\
\hline 69 & 98 & 286 & 9,648438 & 409,752 & 23,55 & 100 \\
\hline 70 & 98 & 286 & 9,765625 & 348,768 & 28,0 & 96,74 \\
\hline
\end{tabular}

In the application of table 2, the presence of a low SOH value $(17,97 \%$ at car $67)$ is noteworthy. That indicates that if this value persists in later measurements the battery must be replaced. It's important to note that the failure resistance value was 
not measured through tests with artificially worn batteries, as performed by I-Kun et al. [5], therefore the low result is only valid for demonstrations purposes.

Adopting the estimated $\mathrm{SOH}$ values, it was possible to evaluate the samples behavior using statistical tools. The graphical demonstration of the Kernel Density Estimator (KDE) below, a method that allows smoothing a curve from a finite sample [8], ensures that the data has been read correctly and that they are within the normal range. In order to deepen the analysis of the cranking voltage, the samples were separated between new vehicles and vehicles with longer usage time as seen in Figure 2. It is noticed that for new vehicles the average voltage is higher than the one seen in used vehicles. Thus, the decay pattern of the battery voltage in the cranking moment with the progression of time in use becomes explicit.

Figure 2. Comparison between Cranking Voltage and vehicle time in service in new vehicles (a) and used vehicles (b)
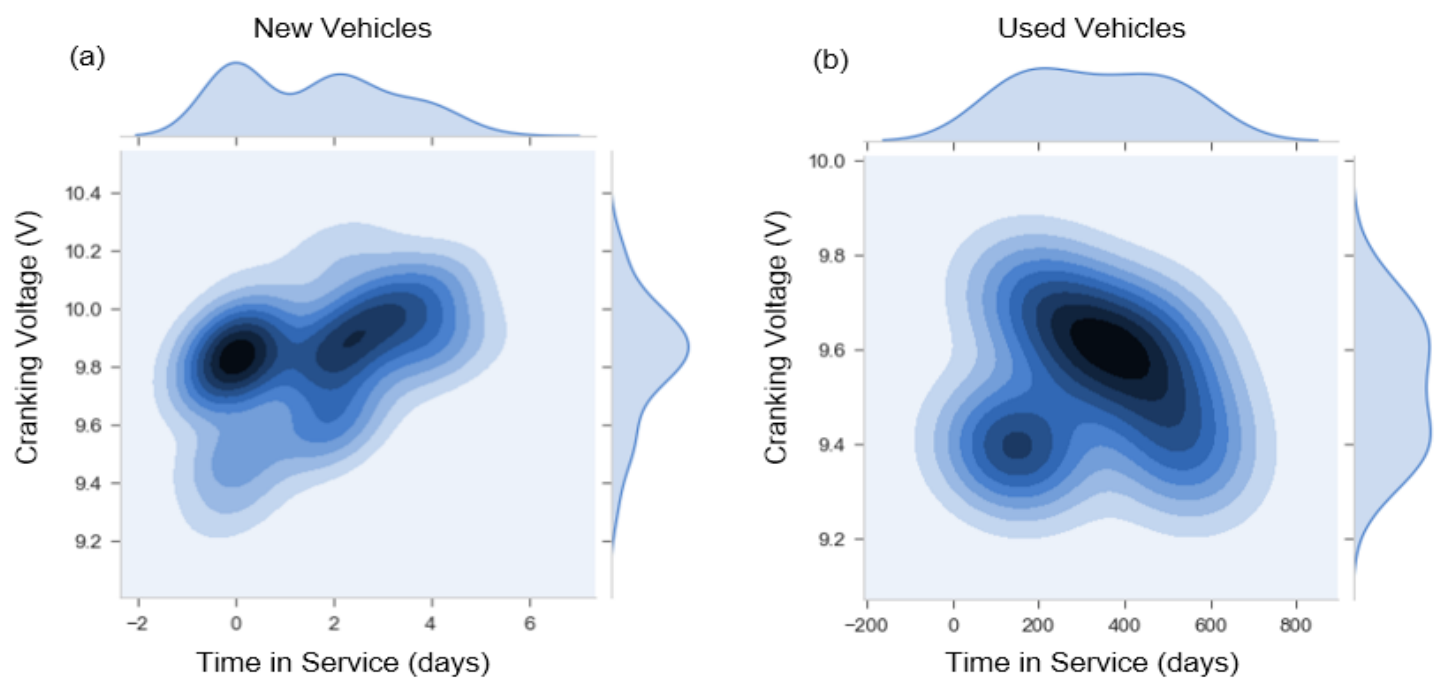

The calculated percentages of $\mathrm{SOH}$ in comparison with the crank duration are displayed in Figure 3(a), demonstrating a higher cranking time associated with the state of health decay. To the right, in Figure 3(b), it's demonstrated the relation between the internal resistance values and the time in service of the vehicles throughout the KDE graphic.

Figure 3. Scatter plot with linear regression between the SOH and Crank Duration of all vehicles (a), KDE relating the vehicle's Internal Resistance and Time in Service (b)
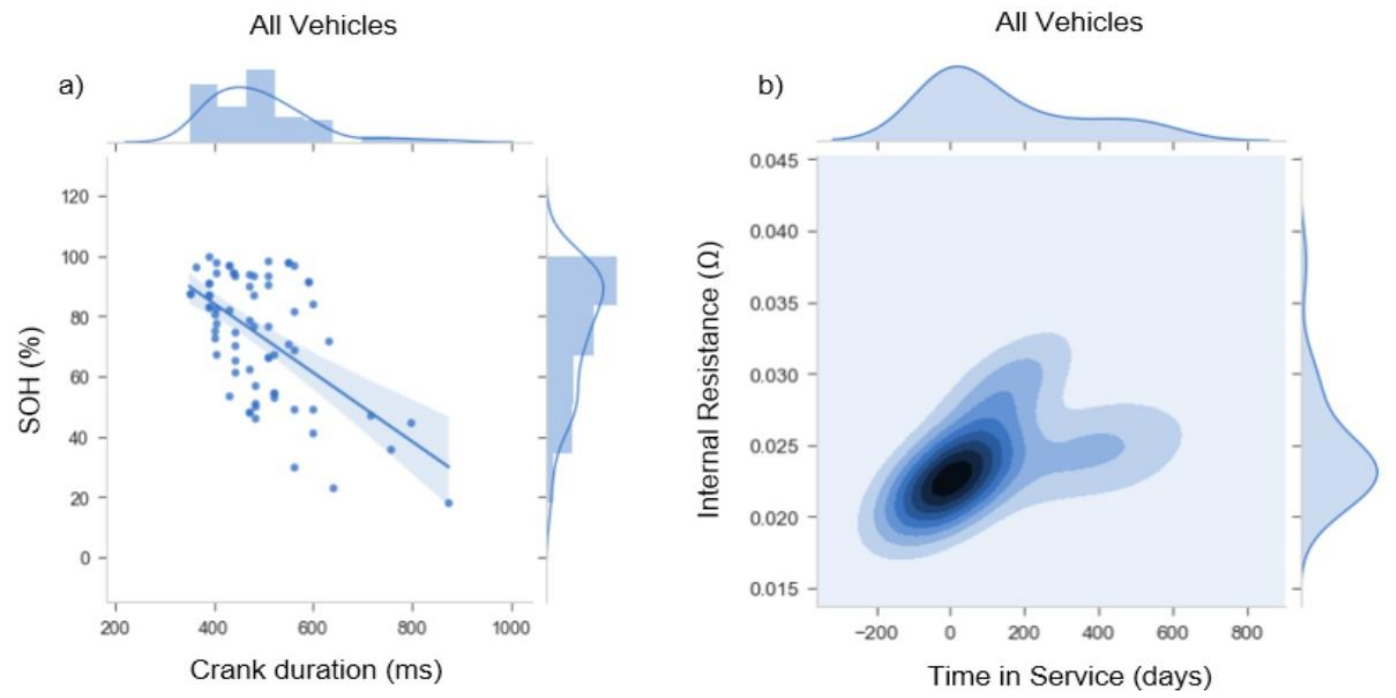
The relation between the internal resistance and time in service of the vehicle is favorable to the expected results, once the resistance increases as the vehicle is used, reflecting the wear suffered by the battery during its use. In addition, the regression curve expressed by the figure 3(a) confirms that the measurement method of health battery demonstrates battery wear, since electric machines energized with currents below nominal have a longer crank duration.

With a validated method, it was possible to develop an implementation proposal on the vehicles HMl (human machine interface) platform. As shown in Figure 4, the symbol establishes an intuitive connection with state of health $(\mathrm{SOH})$ indicator. The heart with negative and positive poles symbolizes the battery health, while the colors around it quickly indicates the $\mathrm{SOH}$ percentage level to the user, which is also shown numerically on the side.

Figure 4. SOH level in vehicle $\mathrm{HMI}$ aplication

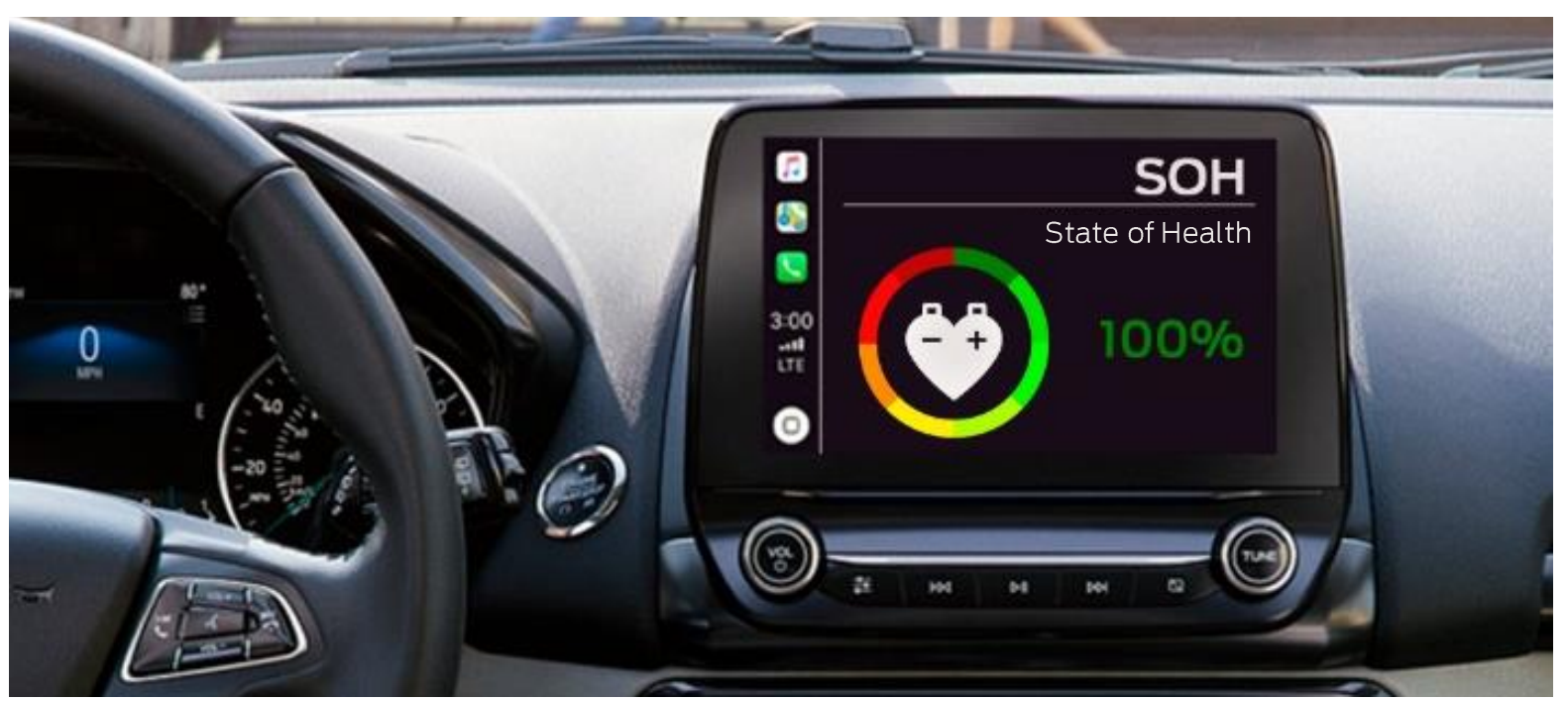

\section{CONCLUSION}

The project demonstrated a mathematical model capable of defining the state of health $(\mathrm{SOH})$ of lead-acid batteries during its lifespan, using collected data. The referred data was used to generate an indicator that shows the $\mathrm{SOH}$ level, based on other parameters previously offered by the diagnostic system of the analyzed vehicles.

As represented in the statistical analysis, the new car data shows a high voltage value that decreases in relation to used cars, an evidence of the battery wear over time. It is also shown that the crank duration is shorter in batteries with better health, which can be linked to the fact that new cars engines start easier and faster. Finally, it can be concluded through the analysis that newer cars have lower internal resistance values, which demonstrates the coherence of the developed method.

Therefore, the study was able to identify and demonstrate a method capable of calculating the $\mathrm{SOH}$ of lead-acid batteries that can be implemented in a customized way by the automaker, partner of this project, without additional components, modules or extra hardware to those already present in the electrical system of the valuated cars.

Next suggested works: increase the sample size of vehicles with longer usage times, including the identification of the failed batteries, increasing results reliability and improving confidence level inside correlations; perform calibrations on certain PIDs to 
obtain more reliable results; development of $\mathrm{HMl}$ platform to present the $\mathrm{SOH}$ to the vehicle user; verify usage of machine learning algorithms to predict $\mathrm{SOH}$ with those parameters, soon as the sample size acquires a good amount of data.

\section{Acknowledgments}

Acknowledgements to Ford Motor Company for the material and support provided and to SENAI CIMATEC for the THEOPRAX methodology indication as an undergraduate final thesis. Special acknowledgements to Rodolfo Exler for guiding the project development from the beginning, giving essential advice, to Roberto Costa, for conceiving the initial idea of the project and providing the necessary tools, to Alexandre Costa for developing the app used in data collection, to Jovelino Torres and Marcelo Moret for revisions and corrections.

\section{REFERENCES}

${ }^{1}$ MDIC, Ministério da Indústria, Comércio Exterior e Serviços. Rota 2030 - Mobilidade e Logística. Available at: <http://www.mdic.gov.br/index.php/competitividadeindustrial/setor-

automotivo/rota2030\#: :text=0\%20Programa\%20Rota\%202030\%20\%2D\%20Mobili dade,um\%20regime\%20tribut\%C3\%A1rio\%20especial\%20para>. Accessed on: 21 Jul. 2020

2 PALMER, Rodrigo Venzke. Estudo da sulfatação durante a formação de placas positivas empastadas de bateria de chumbo-ácido. Curitiba-PR: UFPR, 2008.

${ }^{3}$ GRUBE, Ryan J. Automotive battery state-of-health monitoring methods. 2008. Tese de Doutorado. Wright State University.

4 SUOZZO, Christopher. Lead-acid battery aging and state of health diagnosis. 2008. Tese de Doutorado. The Ohio State University.

5 TSENG, I.-Kun; INAMORI, Mamiko; MORIMOTO, Masayuki. SOH estimation of lead acid battery by artificial deterioration. In: 2014 17th International Conference on Electrical Machines and Systems (ICEMS). IEEE, 2014. p. 861-864.

6 DÜRR, Matthias et al. Dynamic model of a lead acid battery for use in a domestic fuel cell system. Journal of power Sources, v. 161, n. 2, p. 1400-1411, 2006.

7 NAVET, Nicolas; SIMONOT-LION, Françoise. In-vehicle communication networks-a historical perspective and review. University of Luxembourg, 2013.

8 BROCK, Gabriel Martins. Modelagem de volatilidade utilizando modelos GAS semiparamétricos. 2016. 